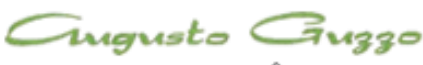

REVISTA ACADEMICA

\title{
Produção enxuta e o just in time: um estudo de caso de aplicação de plataforma e-procurement
}

\author{
Demésio Carvalho de Sousa, Marinalva Barboza, Rose Reis, Rodrigo Franco \\ Gonçalves, Oduvaldo Vendrametto e Ademilson José dos Santos
}

Recebido em: 10/10/2013. Aprovado em: 18/11/2013. Disponibilizado em: 20/12/2013

\section{Resumo}

Impulsionadas por um mercado cada vez mais competitivo, as empresas têm buscado alternativas para atender às expectativas dos consumidores, oferecendo produtos e serviços com qualidade, flexibilidade, agilidade e ao menor custo. Estudos têm evidenciado que o Just in Time (JIT) tem atendido às estas exigências. A combinação da tecnologia da informação, por meio do e-procurement, com o uso do JIT tem potencializado resultados. Este trabalho apresenta, por meio de estudo de caso, os resultados práticos desta combinação em uma empresa multinacional de grande porte do setor de alimentos e bebidas. O objetivo deste artigo é identificar e apresentar os benefícios obtidos com o uso da filosofia JIT na implantação do e-procurement nas áreas de compras e roteirização da empresa.

Palavras-chave: Tecnologia da Informação, Terceirização, Cadeia de Suprimentos.

\begin{abstract}
Driven by an increasingly competitive market, companies have sought to attend consumer expectations by offering the best product, quality, flexibility, agility and cost effectively. Studies have been shown that the Just in Time (JIT) has proven to meet these requirements. Allied to information technology through e-procurement, using the JIT has boosted results. Practical results of this combination are presented in this paper, through a case study in a large multinational company in the food sector. The purpose of this article is to identify and present the benefits of using the JIT philosophy in the implementation of e-procurement in the purchasing and routing company.
\end{abstract}

Keywords: Information Tecnology JIT, e-Procurement Business, Supply Chain 


\section{Introdução}

O Just-in-time (JIT) é uma importante filosofia nas atividades logísticas, especialmente quando se fala em produção enxuta, inicialmente de utilização exclusiva pela Toyota Motor Company na década de 70. Principalmente da década de 80 para cá, a filosofia JIT que é um dos pilares do sistema de produção enxuta tem sido utilizado em empresas de variados segmentos com êxito em vários aspectos como custo, tempo, confiabilidade, qualidade, e flexibilidade (POZO, 2007; CHAN et al., 2010; GIANESI e CORRÊA, 1993).

As variáveis que compõem as atividades primárias e de apoio da cadeia de valor de Porter (1985) sofreram alteração, o estudo de Moori e Zilber (2003) mostra que a aquisição, por exemplo, que refere-se a função de compra de insumos empregados na cadeia de valor, pertencia a atividade de apoio, passou recentemente a pertencer a atividade primária ou gestão logística de operação. Neste contexto, tem a mesma relevância que os insumos adquiridos que incluem desde máquinas, equipamentos, matérias primas, suprimentos e outros itens de consumo que comumente já são associados a atividades primárias.

Ballou (1993) afirma que as atividades primárias são essenciais para o cumprimento dos objetivos logísticos, também são aquelas que contribuem com a maior parcela dos custos logísticos.

As formas de aquisição, parcerias com fornecedores, outsourcing, e-procurement são algumas das estratégias adotadas para melhorar o processo de aquisição e ainda contribuir positivamente para a redução de custos com estocagem e armazenagem.
Chan et al. (2010), após uma extensa revisão da literatura sobre a influência do JIT, puderam identificar que têm um grande impacto na integração JIT com várias atividades logísticas, incluindo suprimento de materiais.

Neste sentido, este trabalho objetiva apresentar os resultados obtidos por uma multinacional americana (chamada XPTO neste trabalho), atuante no mercado brasileiro e produtora de alimentos e bebidas, que através da filosofia JIT, associada a uma ferramenta de e-procurement, proporcionaram uma considerável redução de custo e lead time (tempo) no processo de compras e roteirização da empresa.

\section{Referencial Teórico}

\subsection{Just in Time}

Vivenciando um ambiente pós-segunda guerra mundial, o Japão vislumbrou uma oportunidade de obter vantagem competitiva para otimizar seus processos através da utilização de ferramentas da qualidade e padronização, baseando-se em itens de verificação e controle em todas as etapas do processo produtivo, gerando valor ao cliente. Neste cenário surge a Toyota Motor Company por volta da década de 50. Gianesi e Corrêa (1993) relatam o surgimento do Just in Time (JIT) em 1970, sendo conhecido no ocidente apenas em 1980 como o sistema Toyota de Produção.

O JIT é utilizado no sistema de produção "puxada" onde se produz apenas sob demanda, ou seja, após a concretização de um pedido na quantidade e no tempo desejado, uma vez que não permite antecipação de compras, produção ou transporte.

Slack et al. (2002) relata que "O JIT significa produzir bens e serviços somente no 
momento em que são necessários, para não formar estoques e assim onerar os custos relativos, além de gerar insatisfação do cliente, perda de faturamento e oportunidade de melhoria no fluxo de caixa". O estoque é parte do ativo circulante de uma empresa e influencia diretamente no capital giro. Neste contexto, a filosofia JIT visa atender a demanda instantaneamente, com qualidade perfeita e sem desperdícios. Os autores fazem ainda um comparativo entre a abordagem de um processo tradicional e o JIT, onde ilustra os objetivos conforme figuras 1 e 2 .

a) abordagem de processo tradicional

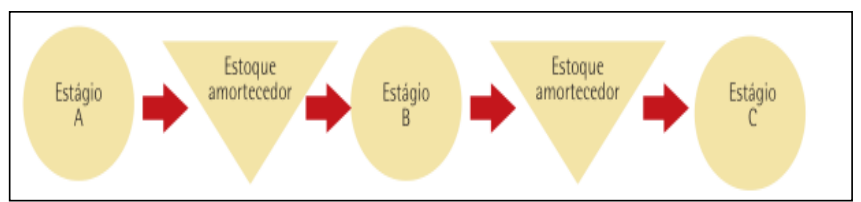

Figura 1: Abordagem de processo tradicional

Fonte: Slack 2002

A abordagem "A" da figura 1 busca cobrir possíveis distúrbios para não prejudicar a produção, utiliza-se de estoques amortecedores entre os processos.

b) abordagem de processo JIT

A figura 2 mostra a abordagem destacase o JIT, que trabalha sem os estoques amortecedores, onde os mesmos são vistos de forma negativa, podendo causar problemas para a empresa.

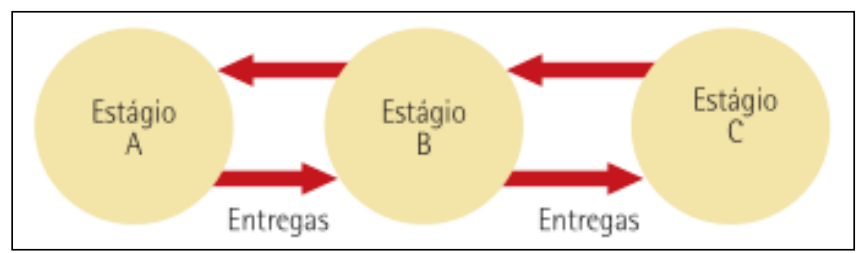

Figura 2: Abordagem de processo JIT

Fonte: Slack 2002

Gianesi e Corrêa (1993) completam que a filosofia vai além de técnicas de administração da produção, incluindo aspectos ligados a materiais, gestão da qualidade, arranjo físico, projeto de produto, organização do trabalho e gestão de pessoas.

Por meio de um estudo do JIT na logística reversa, Chan et al. (2010) revela outras descobertas e contribuição da filosofia nas áreas que abrangem a logística. A figura 3 mostra a falta de integração entre as áreaschave estudadas pelos autores.

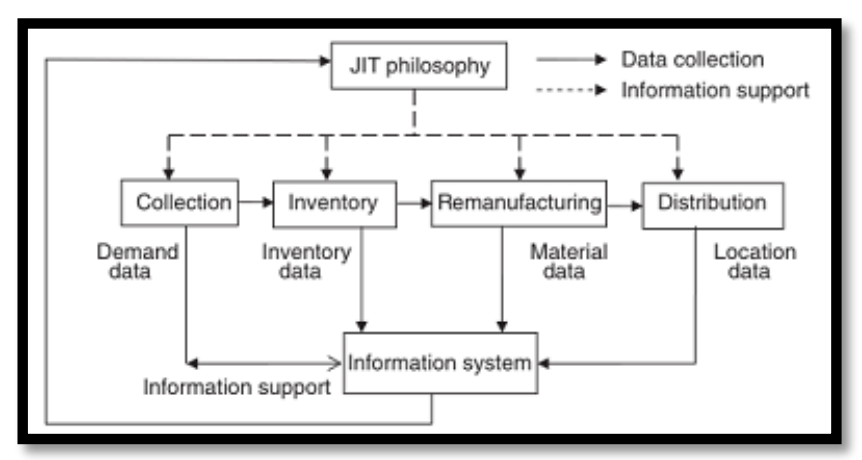

Figura 3: Integração de áreas chave do JIT

Fonte: Chan et al. (2010).

A figura 3 mostra que o sistema de informação pode coletar informações de diferentes áreas no modelo de processo para apoiar JIT e o estoque. Também é importante identificar a relação entre um sistema de informação e desempenho JIT a fim de obter conhecimentos gerenciais úteis em diversas áreas. O desempenho do JIT visa principalmente descobrir como ajudar a otimizar a gestão da produção e relacionadas a ela.

Por meio de uma extensa revisão bibliográfica os autores Chan et al. (2010) puderam obter os resultados de desempenho do JIT em cinco categorias, são elas: custo, a velocidade, flexibilidade, qualidade e confiabilidade.

\subsubsection{Revisão do desempenho do JIT em cinco categorias}

A revisão dos autores mostra claramente o desempenho do JIT mais acentuado na categoria de custo, seguido da velocidade/agilidade, embora bem próximo 
dos resultados de qualidade e flexibilidade. De forma geral o JIT apresenta resultados em importantes aspectos para qualquer organização que deseja ser ou permanecer competitiva e pode ser verificado na figura 4 .

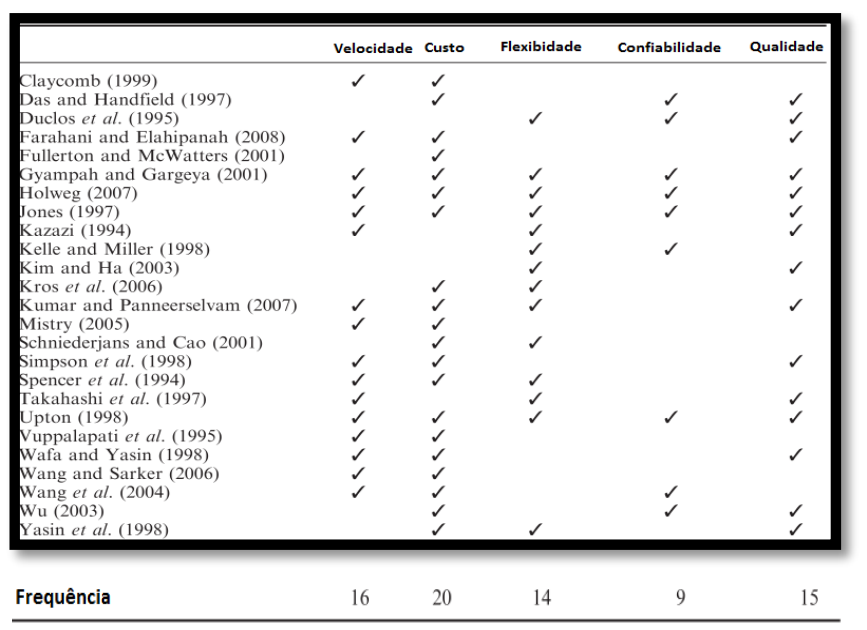

Figura 4: Adaptado

Fonte: Chan et al. (2010).

Liu et al. (2008) acreditam ainda que o JIT contribui para o processo de remanufatura como otimização de linha de produção, envolvendo a aquisição de recursos e o diagnóstico de qualquer atividade com antecedência.

\subsection{E-Procurement}

O e-procurement é uma aplicação de compras baseada na Internet/Intranet ou um serviço alojado que dinamiza as compras dos parceiros de comércio, maximiza a eficiência de comércio ao longo da cadeia de fornecimentos e fornece capacidades estratégicas de e-commerce na Internet (ITRG, 2002).

Iosai, (2005) descreve o e-procurement como sendo o termo usado para descrever o uso dos métodos eletrônicos em todas as etapas do processo de compras desde a identificação dos requerimentos, acordos, pagamentos e potencialmente a gestão dos contratos. Na visão de Presutti (2002) a solução tecnológica do e-procurement facilita as compras cooperativas por meio da Internet. Para o autor, a ferramenta tem o poder de transformar o processo de compra porque se propaga em todos os passos identificados pelo gestor de fornecimento.

Para Brunnelli (1999) a tecnologia de $e$ procurement é definida como uma tecnologia projetada para facilitar a aquisição dos bens por organizações comerciais ou governamentais usando a Internet como suporte.

De acordo com Neef (2001) o $e$ procurement é o aspecto mais revolucionário do B2B e que irá modificar por completo e definitivamente a forma como as empresas fazem negócio, substituindo o processo físico que envolve transações comerciais. Ainda como benefício, Aberdeen (2001) ressalta que a ferramenta evita quantidades massivas de documentos e gera alta eficiência pela automatização dos processos e workeflows associados às compras.

Em suma, a tecnologia automatiza o processo de compras, visando torná-lo mais simples e objetiva maior controle, menor custo no processo de aquisição, avaliação do desempenho dos fornecedores e busca aperfeiçoar o relacionamento entre comprador e fornecedor.

\subsubsection{Comparação dos vários modelos do e-procurement}

Alguns autores dimensionam a importância da área de aquisição de bens e serviços como uma das maiores em custo de produção, estimados entre $50 \%$ e $60 \%$ do seu custo total. A nova forma de gerenciamento da produção aliada ao conceito de JIT, Gerenciamento pela Qualidade Total, dentre outras práticas que buscavam uma maior competitividade no mercado internacional, por meio da redução de custos, contribuíram 
para elevar a função Compras a acompanhar a adoção de novas práticas de gerenciamento para o setor. Desta forma, colocando a área como participante na construção de vantagens competitivas para o negócio. Braga (2006).

Ainda na visão do autor, o mecanismo de implementação prática de conceitos estratégico do strategic sourcing como forma de desenvolver a integração das competências e capacidades dos fornecedores para se obter vantagens competitivas para a empresa compradora. Estas vantagens estão relacionadas com redução de custo e tempo de atendimento de pedidos e disposição de novos produtos no mercado, desenvolvimento de tecnologia, aprimoramento da qualidade e no serviço de entrega. Por fim, o autor sugere que a seleção de fornecedores com participação de outros setores por assumir proporções diversas que vão além do gerenciamento do fornecedor, incluindo capacidade de processo, tecnologia, saúde financeira, requisitos de regulamentação ambiental entre outros.

Quadro 1: Modelos de e-procurement

\begin{tabular}{|l|l|}
\hline $\begin{array}{l}\text { Modelos de comércio } \\
\text { eletrônico }\end{array}$ & Principais características \\
\hline $\begin{array}{l}\text { Redes EDI troca } \\
\text { eletrônica de dados. }\end{array}$ & $\begin{array}{l}\text { Conjunto de pareceres comerciais e } \\
\text { clientes. } \\
\text { Capacidades de transacionais simples. } \\
\text { Processamento em série. Mudança } \\
\text { para redes de valor acrescentado de } \\
\text { forma reativa e dispendiosa. }\end{array}$ \\
\hline $\begin{array}{l}\text { Aplicações de } \\
\text { requisição Business- } \\
\text { to-Employee (B2E) }\end{array}$ & $\begin{array}{l}\text { Compras rápidas para os funcionários } \\
\text { das empresas. Automatização da } \\
\text { aprovação e padronização do processo } \\
\text { de requisição. } \\
\text { Proporciona ao comprador ferramenta } \\
\text { de gestão de fornecedores. }\end{array}$ \\
\hline $\begin{array}{l}\text { Portais de } \\
\text { procurement } \\
\text { empresarial }\end{array}$ & $\begin{array}{l}\text { Melhor controle sobre o processo de } \\
\text { procurement e permite que sejam } \\
\text { implementadas regras de negócio das } \\
\text { empresas de forma mais consistente. } \\
\text { Personaliza com preços negociados } \\
\text { num catálogo multifornecedor. Gestão } \\
\text { da análise de custos. }\end{array}$ \\
\hline
\end{tabular}

\begin{tabular}{|c|c|}
\hline $\begin{array}{l}\text { Trocas comerciais de } \\
\text { primeira geração }\end{array}$ & $\begin{array}{l}\text { Conteúdo industrial, ofertas de } \\
\text { emprego e notícias. Novo canal de } \\
\text { vendas para distribuidores e } \\
\text { fabricantes. Serviços de agregação de } \\
\text { produtos e catálogos. }\end{array}$ \\
\hline $\begin{array}{l}\text { Trocas comerciais de } \\
\text { segunda geração }\end{array}$ & 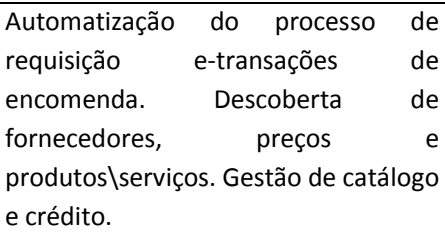 \\
\hline $\begin{array}{l}\text { Trocas comerciais de } \\
\text { terceira geração }\end{array}$ & $\begin{array}{l}\text { Operações sincronizadas e satisfação } \\
\text { em tempo real. Transparência no } \\
\text { processo resultando na restrição de } \\
\text { procura e cadeia de fornecimento. } \\
\text { Informação alternativa para } \\
\text { inventário. }\end{array}$ \\
\hline Consórcios industriais & $\begin{array}{l}\text { Próximo passo na evolução de portais } \\
\text { de procurement empresariais. }\end{array}$ \\
\hline
\end{tabular}

Fonte: Kalakota e Robinson (2000)

Em uma pesquisa aplicada a montadoras automotivas e fornecedores do setor automotivo, Guarniere e Hatakeyama (2010) apresentam os benefícios com a utilização do JIT. Estes autores constataram que $32 \%$ das empresas apontaram redução dos níveis de estoques e espaços físicos, $22 \%$ consideraram redução de perda de materiais e $16 \%$ falaram em redução de custos de compras. Por outro lado, os fornecedores, 32\% afirmaram que adotam na sua atividade LS/compras a ação de qualificação dos fornecedores, $26 \%$ o desenvolvimento de relacionamentos e $17 \%$ a redução do número de fornecedores. A pesquisa também revelou a importância do sistema de informação na melhoria e racionalização dos processos da empresa, além da utilização SI por seus fornecedores. $67 \%$ das empresas consideram que o ERP trouxe melhoria de integração das atividades e $53 \%$ dos seus fornecedores possuem algum tipo de software e $16 \%$ estão em processo de implantação.

\section{Estudo de caso}

A XPTO Brasil, empresa de origem norte-americana, é hoje um dos maiores 
produtores mundiais de alimentos e bebidas em seu segmento.

A identificação dos pontos fortes e fracos da empresa XPTO Brasil foi realizada através de entrevistas com os Diretores de Suprimentos e Tecnologia da Informação da organização, sendo norteada pelo tema e objetivos a seguir:

Tema: Avaliação das necessidades para definição de Planejamento, Armazenagem, Movimentação e Controle de estoques, visando à otimização dos serviços e redução de custos através dos conceitos de Produção Enxuta, Just in Time e aplicação de Plataforma e-procurement.

\section{Objetivos:}

a) Avaliar a aplicação dos conceitos de Just in Time e Produção Enxuta na empresa XPTO Brasil identificando possíveis oportunidades de melhoria.

b) Compreender as principais técnicas para dimensionamento de estoque que atenda às necessidades dos negócios de uma empresa, seu armazenamento e movimentação, focando em Produção Enxuta.

c) Avaliar os resultados obtidos através da aplicação da Plataforma e-procurement e sua melhoria no processo produtivo e no just in time.
Foram apresentados pelos diretores relatórios, impressos, gráficos, planilhas, plantas baixas e estes documentos foram utilizados para identificação dos pontos fracos e oportunidades de melhoria e estes serviram como base para elaboração das propostas seguindo o tema e objetivos préestabelecidos e podem ser visualizados na matriz de SWOT e por se tratarem de informações estratégicas não serão apresentadas em sua totalidade neste artigo.

$\mathrm{Na}$ análise documental foi possível identificar que: "A XPTO Brasil acredita firmemente que o comércio internacional fortalece a estabilidade e a paz ao promover o crescimento econômico, as oportunidades e o entendimento mútuo. Como uma empresa global, reconhece a responsabilidade de agir em harmonia com os legítimos interesses dos países em que faz negócios. Obedecendo toda a legislação e regulamentação vigente nos países em que a sedia".

\section{Análise SWOT}

A identificação dos pontos fortes, fracos, ameaças e oportunidades foi fator critico de sucesso para adequação ao tema e objetivos propostos neste estudo, norteou a incorporação das melhores práticas de mercado e as tecnologias disponíveis seguindo conceitos e metodologia cientifica especifica. Nas primeiras entrevistas, realizadas com o Diretor de Suprimentos da organização foi utilizada a metodologia apresentada no quadro 2 , sendo analisados os ambientes externo e interno da organização focando no tema e objetivos traçados. 
Quadro 2: Analise SWOT

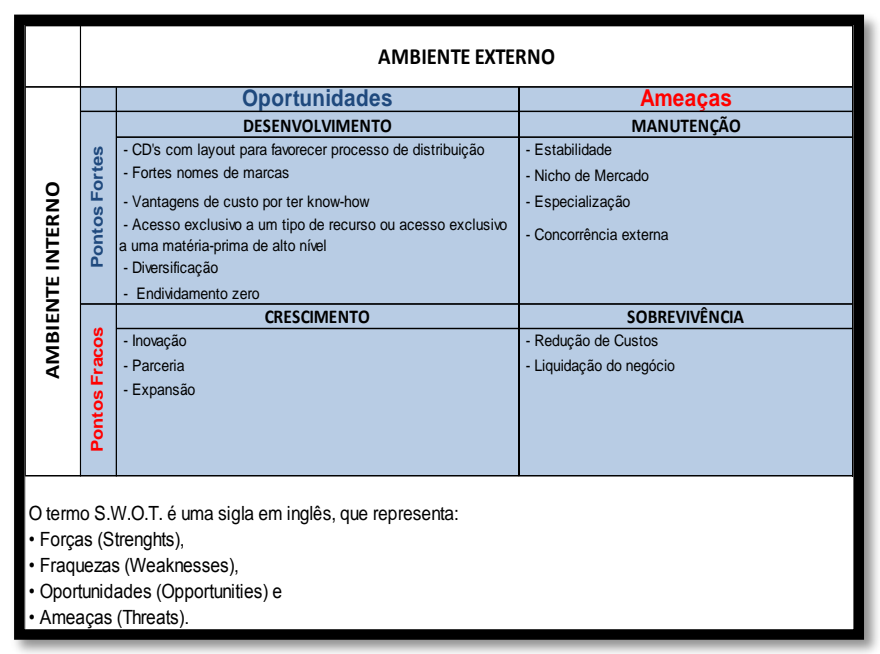

Figura 5: Adaptado

Fonte: Elaborado pelos autores

Após apresentação de conceitos científicos, notou-se a necessidade de readequação dos itens evidenciados e uma adequação do método de pesquisa simplificando as perguntas e a forma de apresentação, ou seja, alguns pontos fortes apresentados na verdade eram oportunidades de melhoria ou pontos fracos, foi necessária uma padronização do conceito de analise de SWOT para evitar novas falhas de interpretação que se segue no texto.

Dentro deste conceito, e a fim de se desenvolver uma visão futura do processo de compras, alinhada com as estratégias corporativas da XPTO Brasil foi escolhida a forma de apresentação simples sem uma matriz, respondendo especificamente ao tema e objetivos traçados, conforme segue.

a) Avaliar a aplicação dos conceitos de Just in Time e Produção Enxuta na empresa XPTO Brasil identificando possíveis oportunidades de melhoria.

Ponto Forte: Visualização de todos os estoques em movimentação da empresa.
Ponto Fraco: Ausência de ações de melhoria e analise dos dados comparando com literatura cientifica.

Oportunidade: Para alicerçar os fundamentos logísticos se faz necessária uma redefinição do layout de um de seus armazéns.

b) Compreender as principais técnicas para dimensionamento de estoque que atenda às necessidades dos negócios de uma empresa, seu armazenamento e movimentação, focando em Produção Enxuta.

Ponto Forte: Sistema ERP (Enterprise Resourse Planning) de Gerenciamento de Rotas e suprimentos.

$>$ Ponto Fraco: Ausência de analise e implementação de melhorias utilizando os dados/informações do ERPSAP associada a metodologia cientifica.

c) Avaliar os resultados obtidos através da aplicação da Plataforma eprocurement e sua melhoria no processo produtivo e no Just in Time.

Ponto Forte: Evidenciada apenas oportunidade de melhoria.

Ponto Fraco: Ausência de integração do ERP (Enterprise Resourse Planning) - SAP com um módulo de Suprimentos, sendo este também não contemplado no core-businnes $\mathrm{da}$ organização. 
Oportunidade: Implementação de uma plataforma de $e$ procurement integrando o ERPSAP com a área de suprimentos, visando à otimização do leadtime, podendo obter ganhos de competitividade e redução de custos operacionais dentro do cenário atual da Logística da XPTO Brasil, conforme fluxo de processo da figura 6 .

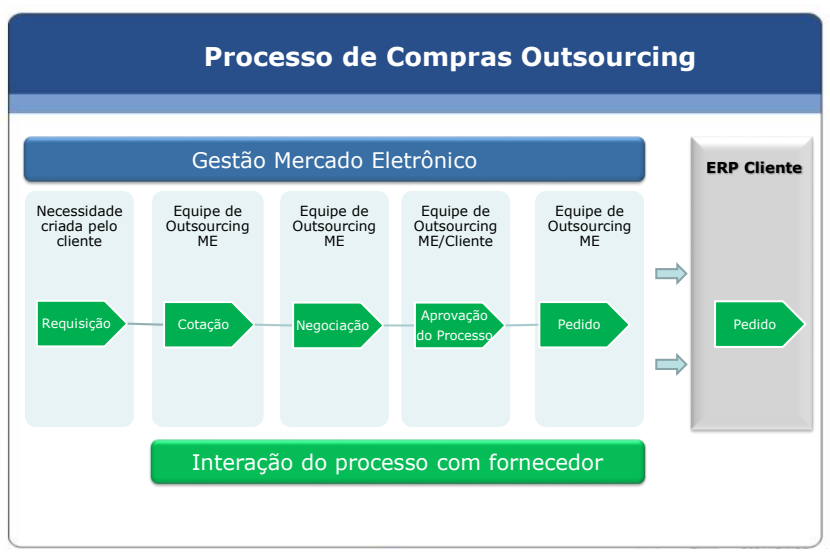

Figura 6: Processo de compras Outsourcing Fonte: Mercado Eletrônico S/A.

\section{Tipo de estratégia corporativa utilizada pela empresa.}

Através da analise documental nota-se que a empresa busca investir na inovação e na melhoria continua de seus produtos e processos tendo um comportamento visionário onde as metas e objetivos planejados são desenvolvidos e controlados, podendo proporcionar a XPTO Brasil a continuidade na busca em se manter como uma das maiores empresas do segmento da América, sempre focando em quais são os fatores críticos de sucesso que devem ser priorizados pela empresa para ouvir a voz dos clientes e partes interessadas norteando a qualidade, custo, flexibilidade, confiabilidade e rapidez. Desta forma apresenta-se como estratégia corporativa da organização a busca por um sistema de distribuição perfeito.

\section{A natureza da estratégia da unidade de negócios da empresa.}

Cada unidade de negócio da XPTO Brasil segue a estratégia corporativa mundial da rede e busca proporcionar as melhores condições de entendimento do benefício dos fundamentos da Logística, sendo que a unidade de negócios escolhida foi um centro de distribuição da empresa e o projeto piloto foi também a unidade estudada para implementação do e-procurement.

Além da proposta de redefinição do layout do armazém, foi necessário compreender as principais técnicas para dimensionamento dos estoques focando na necessidade do negócio da companhia, seu armazenamento, movimentação, estrutura e adequação dos seus equipamentos utilizados para movimentação das mercadorias, também fomentamos aplicar as melhores práticas na área de suprimentos, ou seja, automatizar o sistema de compras de todo o grupo XPTO Brasil através de uma plataforma de e-Procurement integrando o ERP (ENTERPRISE RESOURCE PLANNING) SAP com a área de suprimentos, visando à otimização do leadtime, ganhos de competitividade e redução de custos, sendo esta a estratégia adotada para a unidade Brasil.

\section{A estrutura da empresa e os sistemas} de controle e como eles estão alinhados a estratégia.

Com base nos dados levantados, percebe-se que o tempo de entrega/atendimento está de acordo com a aceitação dos clientes da XPTO Brasil. A empresa se utiliza os modais necessários para aperfeiçoar o atendimento aos diversos tipos de clientes, todos os veículos são de frota 
própria e os demais subcontratados possuem monitoramento via sistema de roteirização GPS, realizado com o intuito de preservação do patrimônio e melhor atendimento ao cliente. É também notada à redução de custos com o transporte, otimizando-se as rotas e diminuindo o tempo de entrega.

Diante dessa realidade, a função armazenagem é relevante para a eficiência do processo logístico, pois acarreta desperdícios quando mal administrada. Assim, decorrente da falta de informação, muitas empresas não enfocam a armazenagem como um causador de custo, tornando-se uma área esquecida, visto as oportunidades de obtenção de lucros encontrarem se, na esfera da administração de materiais.

A utilização de um planejamento nas questões de logística interna na empresa corresponde a um diferencial na atual competitividade das empresas, visto que, esta atividade está diretamente relacionada com custos.

Contudo, o armazenamento não representa apenas união ou seleção de cargas, onde uma sistematização insuficiente dos locais de armazenagem constitui uma das causas básica do aparecimento e do agravamento de uma ampla série de inconvenientes, como: o congestionamento do tráfego, dificuldade na rotatividade de materiais, excesso de movimentos e deslocamentos, má utilização dos meios e do pessoal, etc.

O fluxo da movimentação interna de mercadorias na XPTO Brasil conforme levantamento indica que os produtos são encaminhados à área de recebimento de matéria-prima (área um) para serem limpos, classificados e embalados individualmente. Em seguida, os pacotes já embalados individualmente são agregados em fardos e dispostos na área 2. O beneficiamento dos produtos é feito conforme a diminuição do nível de estoque de produto acabado, sem planejamento com estoque de segurança. Os produtos de terceiros, que não passam pelo beneficiamento, são encaminhados diretamente para a área de estoque de produto acabado, onde são armazenados os que passaram pelo processo de beneficiamento e os que não necessitaram desse processo. Na câmara fria são alocados os produtos perecíveis que necessitam de refrigeração.

Prevenindo-se das incertezas dos fornecedores, a empresa investe em um estoque de segurança de matéria-prima, em sacos de 50kg, para eventuais problemas, garantindo e protegendo a organização, porém esta estratégia apresentou oportunidades de melhoria conforme apresentado neste estudo.

Através da análise do estudo de caso foi possível perceber que o projeto de um armazém deve avaliar muitos fatores em sua inter-relação com o desempenho e os custos da empresa, a fim de encontrar o sistema que otimize as operações. A empresa estudada (XPTO Brasil) mostrou falhas de organização de layout, ocasionadas, pelo falta de planejamento da alta administração, principalmente no tocante ao controle da frota, gerenciamento dos centros de distribuição e otimização do processo de compras através da utilização da Tecnologia da Informação.

A solução de Serviços de Compras (Outsourcing) para a XPTO Brasil buscou atender inicialmente as necessidades de compra de: MRO (manutenção, reparo e operações) para algumas de suas. Caso o piloto tenha sucesso será estendido para as outras 9 (nove) plantas existentes.

A atividade objetiva reduzir a carga dos compradores da XPTO Brasil, e ao mesmo tempo fornecer um serviço com profissionais focados na redução de custos e otimização operacional regulada por índices de Níveis de 
Serviços Acordados - SLA - Service Level Agreement.

\section{Análise dos Resultados}

A figura 7 apresenta o primeiro resultado inicial obtido e ilustra a utilização do ERP em busca da excelência no nível de entrega, primando pela pontualidade e maior satisfação dos clientes, o resultado apresenta uma eficiência de $67 \%$, a pontuação é de (0 a 100) fornecida pelo sistema baseado nos parâmetros pré-estabelecidos, referente a seção de planejamento e controle logístico focando em JIT, onde notam-se vários pontos dispersos.

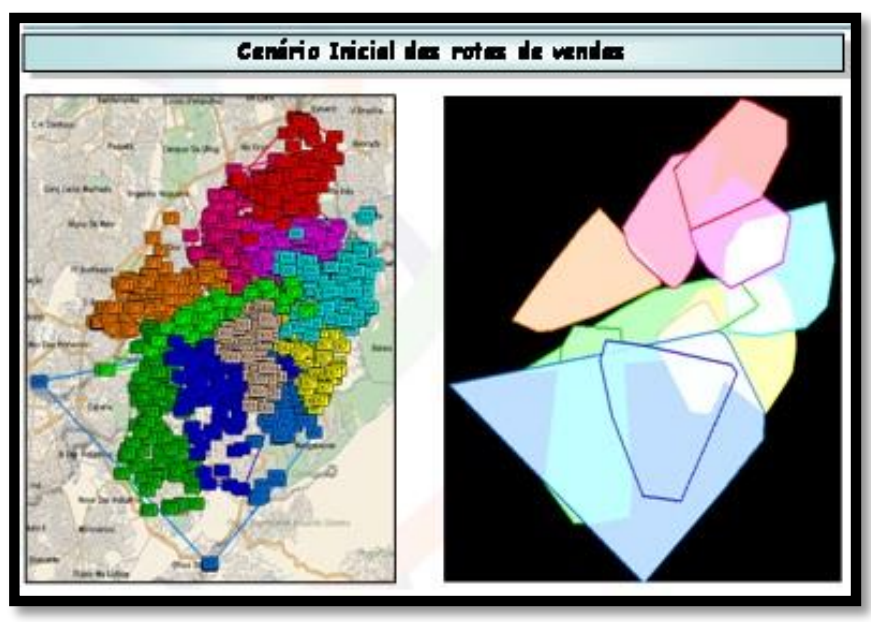

Figura 7: Cenário inicial das áreas e rotas Fonte: XPTO Brasil

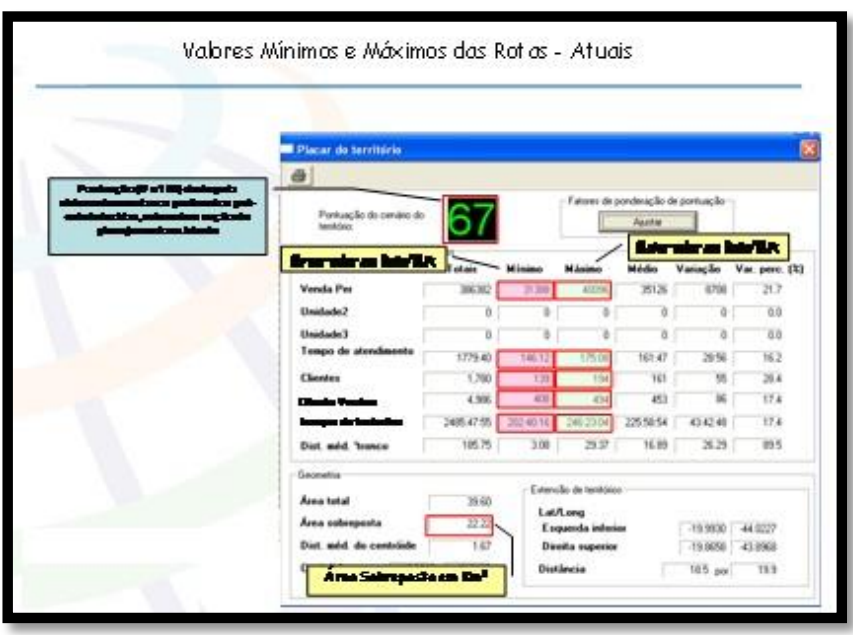

Figura 8: Cenário inicial das áreas e rotas Fonte: XPTO Brasil

As figuras 8 e 9 apresentam as melhorias após adequação dos parâmetros de controle, a melhoria da eficiência chegou a 90\% validando um dos objetivos de JIT, após a utilização do ERP e da plataforma eprocurement na busca da excelência no nível de entrega, primando pela pontualidade e maior satisfação dos clientes.

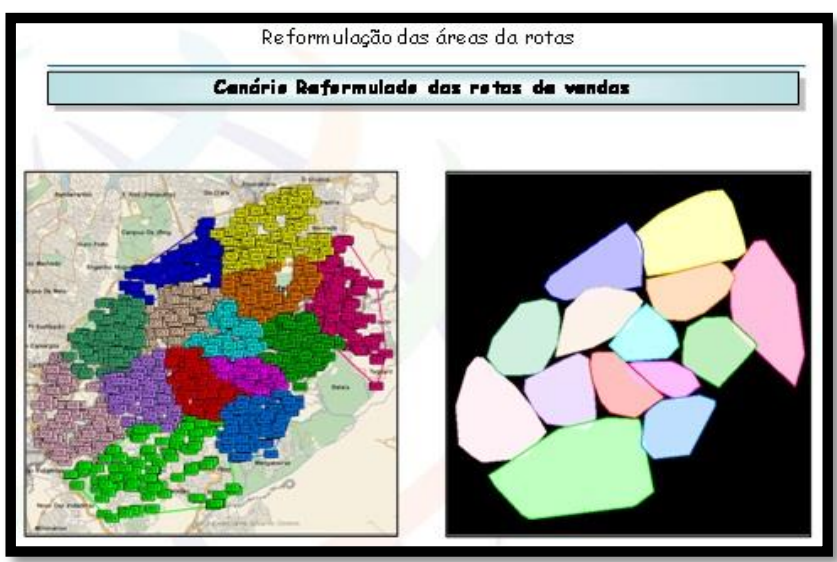

Figura 9: Cenário inicial das áreas e rotas Fonte: XPTO Brasil 


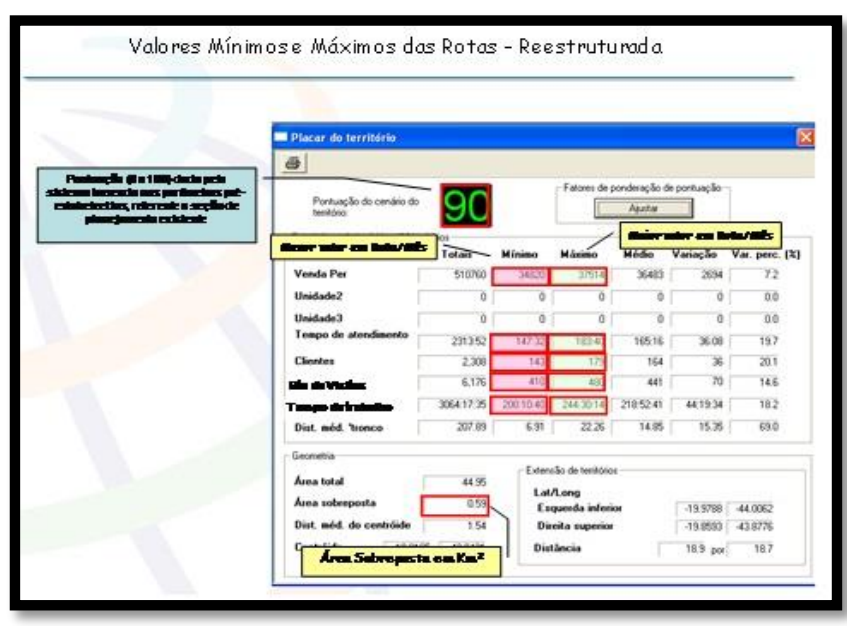

Figura 9: Cenário inicial das áreas e rotas Fonte: XPTO Brasil

Em seguida foram redimensionadas as rotas, conforme figura 10, que otimizou os percursos a fim reduzir as distancias de entregas propostas para os devidos postos de venda os resultados partiram de 1032,77 para 588,31 uma redução de 444,46 na distância a ser percorrida por mês.
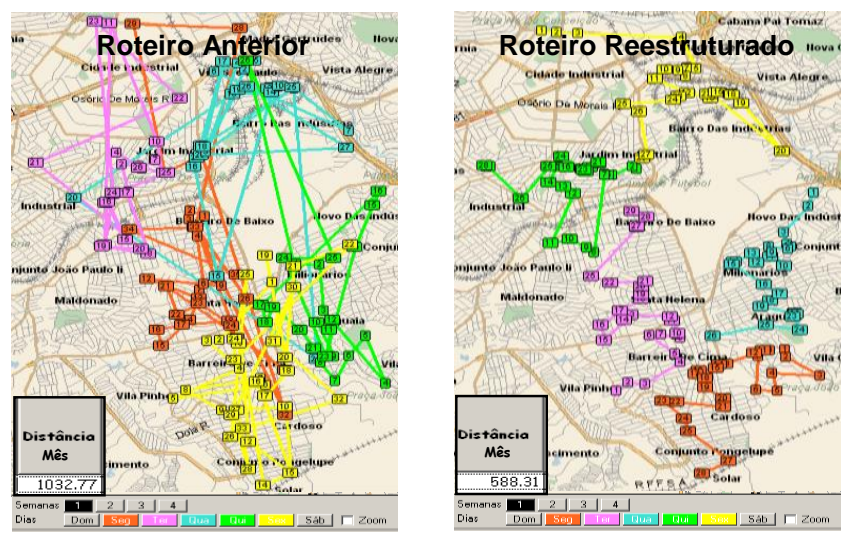

Figura 10: Cenário inicial das áreas e rotas Fonte: XPTO Brasil

Nota-se como resultados obtidos através da reorganização do layout do armazém: $\mathrm{Na}$ situação inicial, a área total disponível para armazenagem ocupava 1.104 $\mathrm{m}^{2}$, sendo $594 \mathrm{~m}^{2}$ ocupados pela área de armazenagem de produtos acabados e após o levantamento bibliográfico foi implementada uma melhoria com a elaboração de um novo layout no qual a área total de armazenagem passa a dispor de $1.284 \mathrm{~m}^{2}$, sendo $714 \mathrm{~m}^{2}$ destinados à área de armazenagem.

Dessa forma, o ganho de espaço físico de $180 \mathrm{~m}^{2}$ e $120 \mathrm{~m}^{2}$ através de um Planejamento Físico da Armazenagem, verificou-se uma distribuição equilibrada das áreas e instalações, permitindo uma redução de custo, como também evitou um retrocesso no fluxo dos materiais beneficiados.

\section{Conclusão}

A Produção Enxuta e a filosofia Just in time associadas a um aplicativo e-procurement proporcionaram à multinacional uma melhora considerável em seu lead time, otimizando o retorno no processo de compras e roteirização planejada da empresa.

Esta mudança estrutural foi sustentada pela adoção das melhores práticas na área de suprimentos, ou seja, automatizar o sistema de compras de todo o grupo da multinacional americana.

Com a implantação da plataforma de $e$ Procurement integrando o ERP (ENTERPRISE RESOURCE PLANNING) SAP com a área de Suprimentos, visando à otimização do leadtime, foi possível observar ganhos de competitividade na área de Suprimentos e a empresa passou a avaliar de forma sistêmica o seu negócio, se adequando ao cenário atual da Logística Empresarial.

\section{Referências Bibliográficas}

1. AlvarEnGA, A. C. \& NOVAES, A.G.

N. (2000) - Logística aplicada: suprimento e 
distribuição física - Editora Edgar Blucher Ltda. $3^{a}$ Edição. São Paulo.

2. BALLOU, H. (1993) - Logística empresarial: transportes, administração de materiais e distribuição física. Editora Atlas. São Paulo.

3. BALLOU, Ronald H. Logística empresarial. São Paulo: Atlas, 1993. HONG, Yuh Ching. Gestão de estoques na cadeia logística integrada. 2. ed. São Paulo: Atlas, 1993

4. BOWERSOX, D. J. \& CLOSS, D. J. (2001)

- Logística Empresarial. Editora Atlas. São Paulo.

5. BRAGA, Ataide, Evolução estratégica do processo de compras ou suprimentos de bens e serviços nas empresas. disponível em http://www.ilos.com.br/web/index.php?op tion $=$ com_content $\&$ view $=$ article $\&$ id $=692 \%$ 3Aartigos-evolucao-estrategica-do-processode-compras-ou-suprimentos-de-bens-eservicos-nas-

presas $\&$ catid $=4 \&$ Itemid $=182 \&$ lang $=$ br

6. BRUNNELLI, M. A., 1999. Purchasing. Consultants see big future on ecommerce.Conference Board, 2001. Research report 1294-01-RR, Conference.Ebusiness strategies in the global marketplace: e-procurement and other challenges..Twente University, Netherlands.
7. CORREAA, L Henrique; GIANESI, Irineu G N; Just in Time, MRPII e OPT: um enfoque estratégico, $2^{a}$ ed., São Paulo: Atlas, 1993.

8. GUARNIERI, Patricia. HATAKEYAMA, Kazuo. Formalização da Logística de suprimentos: caso das montadoras e fornecedoras da indústria automotiva brasileira.

9. HING Kai Chana, SHIZHAO Yinaand Felix T.S. Chanb, Implementing just-in-time philosophy to reverse logistics systems: a review, International Journal of Production Research, Vol. 48, No. 21, 1 November 2010, 6293-6313

10. ITRG (info-tech research group), 2002. A success guide for e-procurement.

London, Canada, International Organizacion of Supreme Audit Institutions, 2005. e-procurement.

11. KAIBARA, M. M. (2005) - A evolução do relacionamento entre clientes e fornecedores - um estudo de suas principais características e contribuições para a implantação da filosofia JIT. Florianópolis/SC. 1998.

12. KALAKOTA, R., ROBINSON, M., 2000. e-business 2.0: road map for success. 13. LIU, S., McMahon, C.A., and CULLEY, S.J., 2008. A review of structured document retrieval (SDR) technology to improve information access performance in 
engineering document management. Computers in Industry, 59 (1), 3-16.

14. MOORI, Roberto Giro, ZILBER, Moisés

Ari. Um estudo da cadeia de valores com a utilização da análise fatorial, Rev. adm. contemp. vol.7 no.3 Curitiba July/Sept. 2003. ttp:/ /dx.doi.org/10.1590/S141565552003000300007

15. MOURA, Reinaldo A. - Série Manual de Logística. Volume 2. São Paulo: IMAM,1997. 16. NEEF, Dale, 2001. e-procurement From Strategy to Implementation. New Jersey, Prentice Hall.

17. NOVAES, A. G. (2001) - Logística e Gerenciamento da Cadeia de Distribuição. Editora Campus. Rio de Janeiro.
18. POZO, H. Administração de recursso materiais e patrimoniais. 2. Ed. São Paulo: Atlas, 2007.

19. PRESUTTII. Jr .W.D., 2002. Industrial marketing management 32. Supply management and e-procurement: creating value added in the supply chain.

20. SLACK, N. Administração da produção. São Paulo: Atlas, 2002.

21. SOUZA, Cesar Alexandre De; SACCOL, Amarolinda Zanela - Sistema ERP no Brasil. Editora Atlas S.A. 1 Edição 2003.

22. TUBINO, D.F. (2000) - Manual de Planejamento e Controle da Produção. Editora Atlas S.A. $2^{a}$ Edição. São Paulo. 